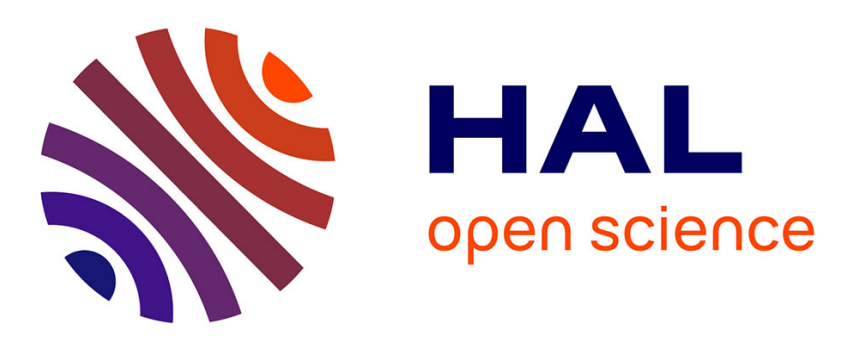

\title{
Photoactive Organic/Inorganic Hybrid Materials with Nanosegregated Donor-Acceptor Arrays
}

\author{
Guillaume Izzet, Xiaolei Zhu, Cheriehan Hessin, Aude Salamé, Lydia \\ Sosa-Vargas, David A Kreher, Chihaya Adachi, Anna Proust, Pierre Mialane, \\ Jérome Marrot, et al.
}

\section{To cite this version:}

Guillaume Izzet, Xiaolei Zhu, Cheriehan Hessin, Aude Salamé, Lydia Sosa-Vargas, et al.. Photoactive Organic/Inorganic Hybrid Materials with Nanosegregated Donor-Acceptor Arrays. Angewandte Chemie International Edition, In press, 10.1002/anie.202014319 . hal-03114586

\section{HAL Id: hal-03114586 https://hal.science/hal-03114586}

Submitted on 19 Jan 2021

HAL is a multi-disciplinary open access archive for the deposit and dissemination of scientific research documents, whether they are published or not. The documents may come from teaching and research institutions in France or abroad, or from public or private research centers.
L'archive ouverte pluridisciplinaire HAL, est destinée au dépôt et à la diffusion de documents scientifiques de niveau recherche, publiés ou non, émanant des établissements d'enseignement et de recherche français ou étrangers, des laboratoires publics ou privés. 


\title{
Photoactive Organic/Inorganic Hybrid Materials with Nanosegregated Donor-Acceptor Arrays.
}

\author{
Xiaolei Zhu, ${ }^{\left[{ }^{[a]}\right.}$ Cheriehan Hessin, ${ }^{[a]}$ Aude Salamé, ${ }^{[a]}$ Lydia Sosa-Vargas, ${ }^{[a]}$ David Kreher, ${ }^{[a]}$ Chihaya \\ Adachi, ${ }^{[b]}$ Anna Proust, ${ }^{[a]}$ Pierre Mialane,${ }^{[c]}$ Jérome Marrot, ${ }^{[c]}$ Aude Bouchet,,${ }^{[\mathrm{d}]}$ Michel Sliwa, ${ }^{[\mathrm{d}]}$ Stéphane \\ Méry, ${ }^{[\mathrm{e}]}$ Benoît Heinrich, ${ }^{[\mathrm{d}] *}$ Fabrice Mathevet, ${ }^{[\mathrm{a}, \mathrm{b}] *}$ Guillaume Izzet. ${ }^{[\mathrm{a}] *}$
}
[a] Dr. X. Zhu, C. Hessin, A. Salamé, Dr. L. Sosa-Vargas, Dr. D. Kreher, Pr. A. Proust, Dr. F. Mathevet, Dr. G. Izzet. Sorbonne Université, CNRS, Institut Parisien de Chimie Moléculaire, IPCM, 4 Place Jussieu, F-75005 Paris, France. E-mail fabrice.mathevet@sorbonne- universite.fr, quillaume.izzet@sorbonne-universite.fr
[b] Pr. C. Adachi, Dr. F. Mathevet
Center for Organic Photonics and Electronics Research (OPERA), Kyushu University, Fukuoka, Japan.
[c] Pr. P. Mialane, Dr. J. Marrot
Université de Versailles Saint-Quentin en Yvelines, Institut Lavoisier Versailles, Université Paris Saclay, UMR CNRS 8180 , F-78035 Versailles cedex, France.
[d] Dr. A. Bouchet, Dr. M. Sliwa
Univ. Lille, CNRS, UMR 8516, LASIRE, LAboratoire de Spectroscopie pour les Interactions, la Réactivité et l'Environnement F-59000 Lille, France.
[e] Dr. S. Méry, Dr. B. Heinrich,
Université de Strasbourg, CNRS, Institut de Physique et Chimie des Matériaux de Strasbourg, UMR 7504, Strasbourg, France. E-mail benoit.heinrich@ipcms.unistra.fr

\begin{abstract}
The synthesis of the first mesogenic donor-acceptor polyoxometalate (POM)-based hybrid is herein described. The structural and electronic properties of the hybrid compound were evaluated through combination of small- and wide-angle $\mathrm{X}$-ray scattering, optical microscopy, electrochemistry and photoluminescence. In the solid state, the compound behaves as a birefringent solid, displaying a lamellar organization in which doublelayers of POMs and bis(thiophene)thienothiophene organic donors alternate regularly. Noticeably, the sub-unit organizations in the composite are similar to that observed for the individual POM and organic donor precursors. Photophysical studies show that in the hybrid, the fluorescence of the organic donor unit is considerably quenched both in solution and in the solid state, which is attributed to occurrence of intramolecular charge-separated state.
\end{abstract}

The control of the molecular organization in semiconducting thin films is a key point for improving their optoelectronic performances. ${ }^{[1]}$ For instance, self-organization of electron donor (D) and acceptor (A) moieties into highly ordered molecular architectures is extremely promising for electronic and photovoltaic applications owing to the existence of ideal percolation pathways for both holes and electrons via the formation of nanosegregated $D$ and $A$ domains. ${ }^{[2]}$ The realization of nano-structured arrays displaying regularly alternated $D$ and $A$ subdomains is still quite challenging, since they are entropically unfavorable. ${ }^{[3]}$ Furthermore, $\mathrm{D}$ and $\mathrm{A}$ often tend to stack on one another as a result of their electronic complementarity, ${ }^{[4]}$ which prevents the percolation of both electrons and holes. To circumvent this, an effective strategy relies on the design of D-A systems with $D$ and $A$ units of distinct chemical natures to induce their nanosegregation. This usually involves the addition of a competitive interaction (covalent, ${ }^{[3 a, 5]}$ hydrogen bond, ${ }^{[6]}$ host guest, ${ }^{[7]}$ steric repulsion, ${ }^{[4]}$ void filling ${ }^{[8]}$ ) to the $\pi-\pi$ interactions between the $\pi$-conjugated $D$ units. As regards electrostatic interactions, while ionic liquid crystals have been widely investigated $^{[9]}$ a limited number of ionic D-A systems have been achieved $^{[10]}$ since it requires to overcome the electrostatic repulsions between identical charges. ${ }^{[11]}$ Ionic liquid crystals have attracted much attention in the field of energy conversion because of their potential to act as ion-conductive electrolyte materials for dye sensitized solar cell and fuel cell applications ${ }^{[9,12]}$ but they have been much less investigated for optoelectronics applications. ${ }^{[10]}$ The elaboration of hybrid systems combining organic and inorganic sub-components are more and more considered for the development of next-generation optoelectronic materials as they could combine benefits of the organic and inorganic components. ${ }^{[13]}$ Among the different inorganic building units, polyoxometalates (POMs) are currently drawing an important attention. ${ }^{[14]}$ These nanosized polyanionic oxoclusters have been considered as ideal models for understanding the selfassembly process of liquid crystalline organic-inorganic hybrids because of their discrete structural character. ${ }^{[15]}$ POMs are also emerging in areas related to energy conversion/storage and information technology owing to their remarkable electron reservoir properties. ${ }^{[16]}$ The formation of POM-based mesomorphic materials has been mostly realized by ion exchange reactions with mesogenic cations, yielding surfactantencapsulated POMs. ${ }^{[15,17]}$ Only few examples of covalent POMmesogen hybrids have been reported so far, ${ }^{[18]}$ while the covalent functionalization of POMs offers many assets such as a better control of the structure, composition and directionality between the organic and inorganic parts. In all these reported systems (electrostatic and covalent), the mesogen units were not designed as photoactive units and these work mostly focused on the study of the polymorphism. We herein report the first example of a photoactive donor-acceptor POM-based material based on the association of a Keggin-type POM to four bis(thiophene)thienothiophene (BTTT). We demonstrate that the antagonistic chemical nature of the inorganic and organic parts leads to a nanosegregation of both units into mesomorphic structures characterized by the formation of distinct, regularly alternated $D$ and $A$ subdomains. Concomitantly, this material shows significant lower luminescence than the parent BTTT compounds, which is indicative of charge transfer between the $D$ and $A$ units. 


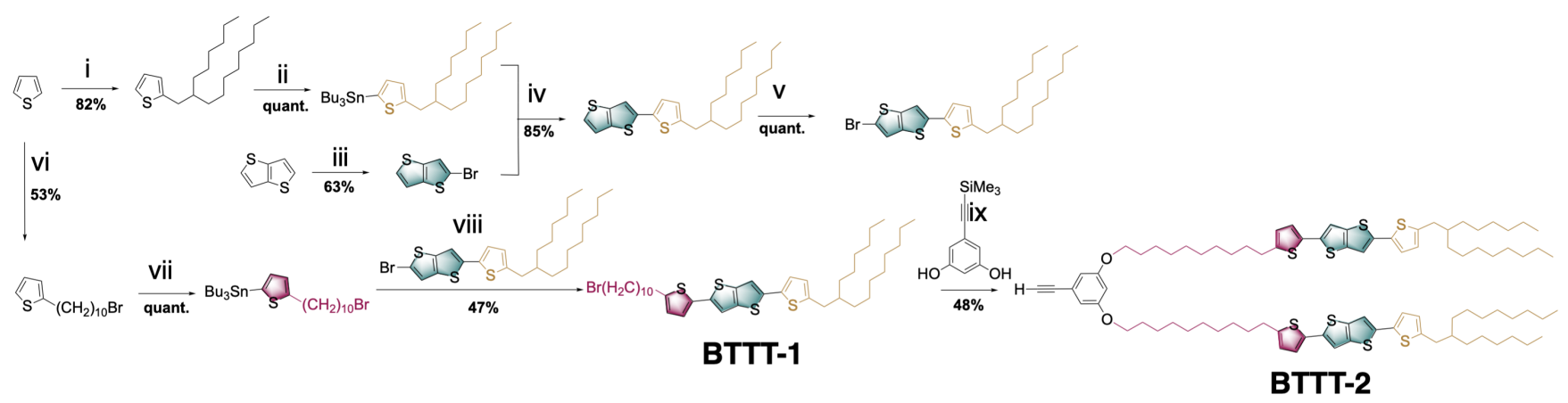

Scheme 1. Synthesis of the dimeric BTTT precursor BTTT-2.

Organo derivatives based on monovacant POMs have axial topologies that should be prone to promote lamellar structures when associated to calamitic derivatives. As the target compound should display a (high temperature) liquid crystalline behaviour induced by the organic parts allowing an efficient device processing, the electrostatic interactions between the ionic moieties should not surpass the global $\pi-\pi$ and Van der Waals interactions. Among the different hybrid POM-based platforms that some of us developed (i.e., organotin and organosilyl derivatives of monovacant Keggin- and Dawson-type POMs), ${ }^{[16 c]}$ we selected the Keggin-type organosilyl one since it displays the best electron accepting properties and have the highest organic vs inorganic ratio. We indeed showed that, when grafted to a photoactive unit, Keggin-type organosilyl derivatives displayed the fastest photoinduced charge injection (ca. 50 ps). ${ }^{[19]}$ Keggintype POMs have a diameter of ca. $1 \mathrm{~nm}$ and $\pi$-conjugated molecules usually stack with a $\pi-\pi$ distance of 3.3-3.5 $\AA{ }^{[20]}$ We then estimate that at least 4 organic mesogen units should be necessary to counterbalance the size of the POM units. As regards the organic part, we selected BTTT since this calamitic compound is a good electron donor and displays a high-energy excited state that should perform charge transfer onto the Keggin platform. We thus developed the synthesis of a dimeric BTTT molecular precursor named BTTT-2 involving a 9-step reaction (Scheme 1). This compound contains two BTTT units terminated by a ramified aliphatic chain (improving its solubility) and connected to a central aryl unit through linear $\mathrm{C}_{10}$ aliphatic chains, commonly used in complex mesomorphic systems. ${ }^{[3 c, 21]}$

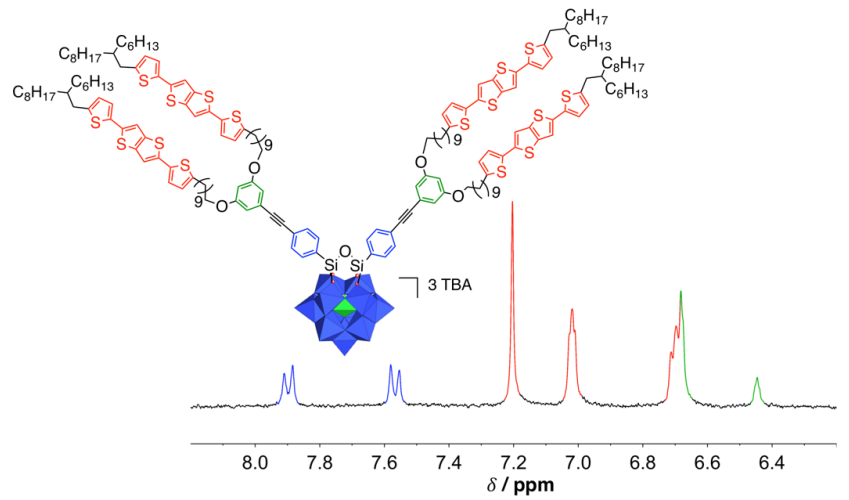

Figure 1. Molecular representation and enlargement of the aromatic ppm region of the ${ }^{1} \mathrm{H}$ NMR of $\mathrm{Ksi}$ [BTTT-2] (300 MHz, $\mathrm{CD}_{2} \mathrm{Cl}_{2}$ ).
The presence of flexible aliphatic chains that separate the different redox active units is indeed of crucial importance for the mesomorphic organization. The aliphatic chains should be long enough to allow sufficient mobility of the mesogenic and POM moieties for their nano-segregation and mutual organization, and they are also even required for the adjustment of the molecular volumes in the molecular packing. Yet, too long insulating aliphatic chains should be precluded as they are expected to slow down the kinetics of photoinduced electron transfer. The precursor BTTT-2 also contains a terminal alkyne bond that is further coupled to the bis-iodo aryl terminated POM-based hybrid platform $\left[\mathrm{PW}_{11} \mathrm{O}_{39}\left\{\mathrm{O}\left(\mathrm{SiC}_{6} \mathrm{H}_{4} \mathrm{I}\right)_{2}\right\}\right]^{3-}$, named $\mathrm{Ksi}_{\mathrm{i}}[\mathrm{l}]$, through a Sonogashira cross-coupling reaction, as previously developed by some of us. ${ }^{\left[16 \mathrm{c},{ }^{22]}\right.}$ The resulting hybrid, named $\mathrm{K}_{\mathrm{si}}$ [BTTT-2], with molecular formula $\left(\mathrm{C}_{16} \mathrm{H}_{36} \mathrm{~N}\right)_{3}\left[\mathrm{PW}_{11} \mathrm{O}_{39}\left\{\mathrm{O}\left(\mathrm{SiC}_{94} \mathrm{H}_{125} \mathrm{O}_{2} \mathrm{~S}_{8}\right)_{2}\right\}\right]$, was isolated as a tetrabutyl ammonium salt. It was characterized by ${ }^{1} \mathrm{H}$ and ${ }^{31} \mathrm{P}$ NMR spectroscopies, elemental analysis, mass spectrometry and FT-IR spectroscopy (Figures 1 \& S1-S10).

Cyclic voltammetry of $\mathrm{Ksi}$ [BTTT-2] in solution $\left(\mathrm{CH}_{2} \mathrm{Cl}_{2}\right.$ / TBAPF $_{6} 0.1 \mathrm{M}$ ) attests the donor-acceptor character of the hybrid. In the oxidation part, $\mathbf{K s i}_{\mathbf{s}}$ [BTTT-2] displays an oxidation feature at $0.3 \mathrm{~V} \mathrm{vs} \mathrm{Fc}^{+} / \mathrm{Fc}$ corresponding to the one-electron oxidation of BTTT units (Figures 2 \& S11-12). Interestingly, the oxidation potential of $\mathrm{Ksi}_{\text {[BTTT-2] }}$ is considerably negatively shifted compared to that of the precursor BTTT-2, by ca. $150 \mathrm{mV}$.

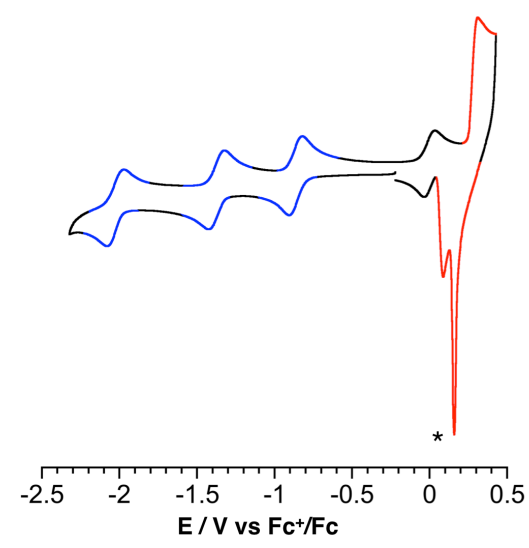

Figure 2. Cyclic voltammogram of $\mathbf{K}_{\mathbf{s i}}$ [BTTT-2] in $\mathrm{CH}_{2} \mathrm{Cl}_{2}$ / $\mathrm{TBAPF}_{6}$ containing ferrocene. The red and blue waves correspond to redox processes located on the BTTT and POM units, respectively. The peaks noted with an asterisk correspond to the reduction and desorption of the oxidized hybrid at the working electrode. The process at $0 \mathrm{~V}$ comes from ferrocene standard. 
This is attributed to the electrostatic stabilization of the oxidized species by the polyanionic framework, which is amplified by the flexible character of the aliphatic spacer chain and suggests a folding of the oxidized BTTT units towards the POM (note that no significant potential shift is observed in these families of hybrids when rigid organic moieties are grafted onto the POM unit). ${ }^{16 c, 19 a}$ ${ }^{23]}$ The shape of the wave of the oxidation process is characteristic of adsorption of the oxidized species at the working electrode. The reduction of the oxidized species occurs in a two-step pathway, which is indicative of a cooperative process owing to the possible folding of oxidized BTTT units. In the reduction part, three reversible monoelectronic reductions of the polyoxometalate framework occur at $-0.86 \mathrm{~V},-1.37$ and $-2.02 \mathrm{~V}$ vs $\mathrm{Fc}^{+} / \mathrm{Fc}$ and are similar to that of the parent platform $\mathrm{K}_{\mathrm{si}}[\mathrm{l}]$.

Consistently with the DSC curves, the polarizing optical microscopy observations of BTTT-2 show that it exhibits a pastelike birefringent mesophase from room temperature to the transition as to isotropic liquid at $69^{\circ} \mathrm{C}$ (Figures S13-S14). The high transition enthalpy $(44 \mathrm{~J} / \mathrm{g})$ and the low transition temperature hysteresis $\left(6^{\circ} \mathrm{C}\right)$ are indicative of a mesophase with a cohesive and highly-ordered structure. ${ }^{[24]}$ Thermogravimetric analysis of $\mathrm{Ks}_{\mathrm{si}}[\mathrm{BTTT}-2$ ] shows that the hybrid is quite thermally stable up to $300^{\circ} \mathrm{C}$ (Figure S15). $\mathrm{K}_{\mathrm{si}}$ [BTTT-2] is a birefringent solid at room-temperature that softens to a very viscous mesophase above $70-80^{\circ} \mathrm{C}$ (Figures S13-S14). No phase transition was observed on further heating to $300^{\circ} \mathrm{C}$ but a broad step-like transition attributed to a glass-like transition freezing the mesophase structure was evidenced. ${ }^{[21 \mathrm{c}]}$ The transitional range from roughly $70^{\circ} \mathrm{C}$ to $100^{\circ} \mathrm{C}$ coincides indeed with the softening/rigidification of the sample during POM observations.

The structural arrangement of BTTT-2 was inferred by smalland wide-angle X-ray scattering (SWAXS) (Figure S16). The dimeric precursor BTTT-2 exhibits a multi-layered lamellar structure (lam) formed of two BTTT and one ethynylaryl (EA) layers alternating with spacer and terminal chain layers. Geometrical self-assembly parameters and discussion of selfassembly within layers and into lamella are given in ESI (Table S2). These structural data were needed for modelling the selfassembly of $\mathrm{K}_{\mathrm{si}}[\mathrm{BTTT}-2$ ].

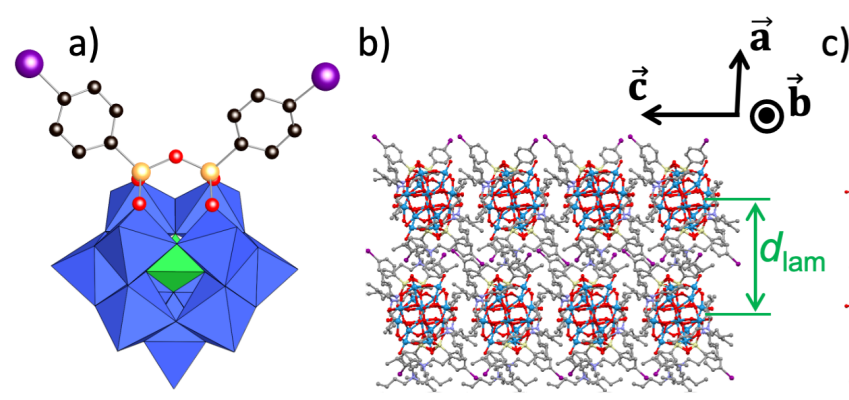

To evaluate the molecular packing of Keggin-type hybrid POMs as tetrabutyl ammonium salts, single crystals of the hybrid parent $\mathbf{K}_{\mathbf{s i}}[\mathbf{l}]$ were grown by slow diffusion of methyl tert-butyl ether into an acetonitrile solution of $\left.\mathrm{Ksi}_{\mathrm{I}} \mathrm{l}\right]$. The structure of $\mathrm{Ksi}_{\mathrm{si}}[\mathrm{l}]$ (Table S1) is constituted of a $\left\{\mathrm{PW}_{11} \mathrm{O}_{39}\right\}$ unit covalently functionalized by a $\left\{\mathrm{O}\left(\mathrm{SiC}_{6} \mathrm{H}_{4} \mathrm{I}\right)_{2}\right\}$ fragment, each silyl group being linked to two different terminal oxygen atoms of the lacunary POM site (Figure 3a), with three TBA acting as counterions. The Si-O and $\mathrm{Si}-\mathrm{C}$ bond lengths are in the expected ranges (1.60-1.63 $\AA$ and 1.83-1.86 $\AA$, respectively) for an organosilyl derivative of a Keggin-type POM. ${ }^{[25]} \mathbf{K s i}_{\mathrm{si}}[\mathrm{l}]$ self-assembles into monolayers of POM units (Figure $3 \mathrm{~b}$ ) with silyl groups alternately oriented up and down (Figure 3c). Two over three TBA ions intercalate between POM units in the layer plane, while the other TBA ion constitutes an interlayer with the iodophenyl substituents. The superimposition of these molecular layers defines a lamellar periodicity $d_{\mathrm{lam}}=15.39 \AA$ and a molecular area $A_{\mathrm{mol}}=V_{\mathrm{mol}} / d_{\mathrm{lam}}=$ 155.6 $\AA^{2}, V_{\mathrm{mol}}=V / Z=2394 \AA^{3}$ being the volume of the hybrid and its counter ions. The in-plane arrangement of POM and TBA follows a rectangular lattice (Figure $3 \mathrm{~d}$ ), with periodicity of two molecules along $b$-axis due to alternative POM orientations and of two rows along $c$-axis $(b=26.974 \AA, c=23.069 \AA, Z=4)$. This geometry comes down a slightly distorted hexagonal lattice, since the lattice parameter ratio $(c /(b / 2)=1.710)$ differs from hexagonal case $(\sqrt{ } 3)$ by only $1.25 \%$. Reason is that the counter ions arrange in an almost regular honeycomb lattice around POM units, as allowed by $2: 1$ in-plane stoichiometry and the relatively large volume of TBA. Conversely, the choice of the cation might be critical for properties as its volume fraction could discriminate between ionic arrangements and affect the POM spacing within layers

Investigation of $\mathrm{Ksi}[\mathrm{BTTT}-2]$ by SWAXS revealed a mesomorphic, multilayered lamellar structure with rectangular inplane arrangement (lam Rec $)$. Specifically, patterns exhibit $(h 00)$ reflection series of a lamellar substructure alternating a POM layer and several, in comparison to POM, low-electronic density aromatic and aliphatic layers (Figure 4). The mid- and wide-angle region contains series of $(0 \mathrm{kl})$ reflections from two-dimensional arrangement of POM and TBA, in addition to the broad scattering signals $h_{c h} / h_{a r}$ from lateral packing within organic layers.

Figure 3. Left: Combined polyhedral/ball-and-stick representation of $\mathrm{K}_{\mathrm{si}}[\mathrm{l}]$. Solvent molecules and counterions have been omitted for clarity. $\mathrm{WO}_{6}$ and $\mathrm{PO}_{4}$ polyhedra are shown in blue and green, respectively. The $\mathrm{Si}, \mathrm{O}, \mathrm{C}$ and I atoms are shown in orange, red, black and purple respectively; b) rows of aligned POM units directed along $b$-axis and assembled into layers in the $b \times c$ plane; $d_{\text {lam }}$ is the lamellar periodicity; $c$ ) side-view of the rows evidencing the alternative up and down orientation of substituents; d) rectangular sublattice (green frame) formed by the honeycomb arrangement of TBA around POM (red dotted lines). 

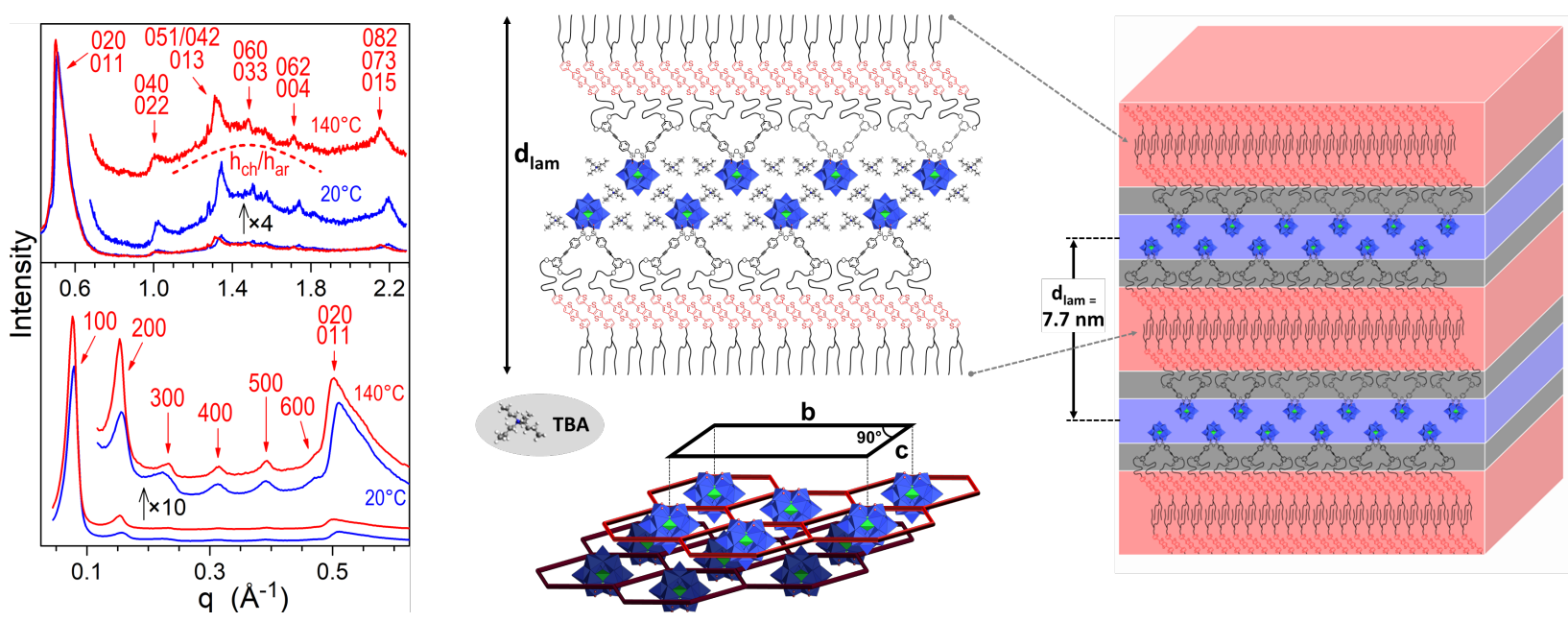

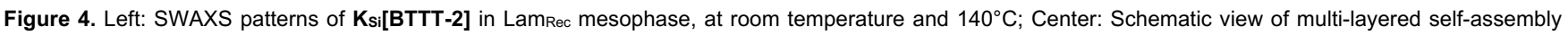
model and rectangular arrangement of POM-TBA double-layers (POM in blue; TBA honeycomb in red; bottom layer with lateral offset in dark colours); Right: 3D schematic representation of $\mathbf{K}_{\mathbf{s i}}[\mathrm{BTTT}-2]$ arrangement respecting molecular segment sizes and shapes.

The absence of mixed $(h k l)$ reflections and the tailing of main $(0 \mathrm{kl})$ reflections imply that lamellae can slip on top of each other and form a smectic-like multi-layered structure. The lamellar sequence involves two molecular layers with double-layers of POM-TBA and of branched chains (Figure 4). The lamellar periodicity, varying with temperature between 77 and $82 \AA$, corresponds to $A_{\text {mol }}$ values close to $180 \AA^{2}$, which agrees with the space requirement of the two BTTT-2 branches and exceeds $A_{\mathrm{mol}}$ of precursor $\mathrm{K}_{\mathrm{si}}[\mathbf{l}]$ by about $14 \%$. The rectangular POM-TBA arrangement nevertheless maintains the quasi-hexagonal geometry $(b / c \approx \sqrt{ } 3)$ of the precursor, but with EA branches all oriented on the same side of POM-TBA layers, reducing de facto the periodicity along $c$-axis to a single molecular row (Table S2). The opposite layer sides are nested and form double-layers, whose configuration is revealed by the intensity modulation in the $(0 \mathrm{kl})$ series, in particular the undetectable $(031) /(002)$ group compared to intense $(040) /(022)$ and $(051) /(042) /(013)$ groups. Specifically, both expanded layers are laterally shifted, the POM units of one layer being located in the tetrahedral voids of the other layer (Figure 4).

Preliminary photophysical studies of the hybrid have been conducted. Absorbance spectrum for Ksi[BTTT-2] shows the additivity of the POM $\left(\lambda_{\max }=280 \mathrm{~nm}\right)$ and BTTT-2 $\left(\lambda_{\max }=380 \mathrm{~nm}\right)$ absorptions. The fluorescence ( $\lambda_{\text {exc }}=380 \mathrm{~nm}$ ) of the BTTT units in $\mathbf{K}_{\mathrm{si}}$ [BTTT-2] is ca. twice lower to that of BTTT-2 both in the solution ( $\phi=10 \%$ vs $22 \%$ respectively) and the solid state $(\phi \approx 1 \%$ vs $2 \%$ ) as shown in Figures 5 and S17. In solid state, emission maxima are red-shifted compared to solution, which is assigned to intermolecular interactions. The fluorescence quenching in solution is also evidenced by shorter average emission lifetimes in $\mathbf{K}_{\mathrm{si}}$ [BTTT-2] compared to BTTT-2 (Figure S18 and Table S3). While BTTT-2 emission decay is almost mono-exponential with a lifetime of about 450 ps ( $99 \%$ of the decay), two shorter lifetimes are needed for $\mathrm{K}_{\mathrm{si}}$ [BTTT-2] to describe $98 \%$ of the decay, $163 \mathrm{ps}$ $(18 \%)$ and 331 ps $(80 \%)$. Such decrease and multiexponential decays should be linked to the existence of different conformers in solution and the existence of competitive non radiative processes (i.e. formation of charge transfer state and triplet state). Indeed the quenching can be favoured by the folding of the BTTT units toward the POM, as suggested above by cyclic voltammetry, which could accelerate charge transfer or favour the formation of triplet state through heavy atom effect. In the solid state, taking into account the similar layered molecular packing of the nanosegregated BTTT units in Ksi[BTTT-2] and BTTT-2 thin films, we attribute the significant difference of luminescence between these species to the occurrence of charge transfer (note that energy transfer from the excited BTTT to the POM is unlikely as POMs units only absorb in the UV-part of the solar spectrum). We indeed observed that the tilt of the BTTT units within the layers, imposed by the branched terminal aliphatic chain, decreases the distance between the POM and BTTT units to ca. $1.9 \mathrm{~nm}$, as indicated by the structural modeling of the molecular organization from SWAXS data. ${ }^{[26]}$ This value that is similar to that between POM and Bodipy units for which we already observed efficient charge injection from the Bodipy to the POM. ${ }^{[19 a, 23]}$

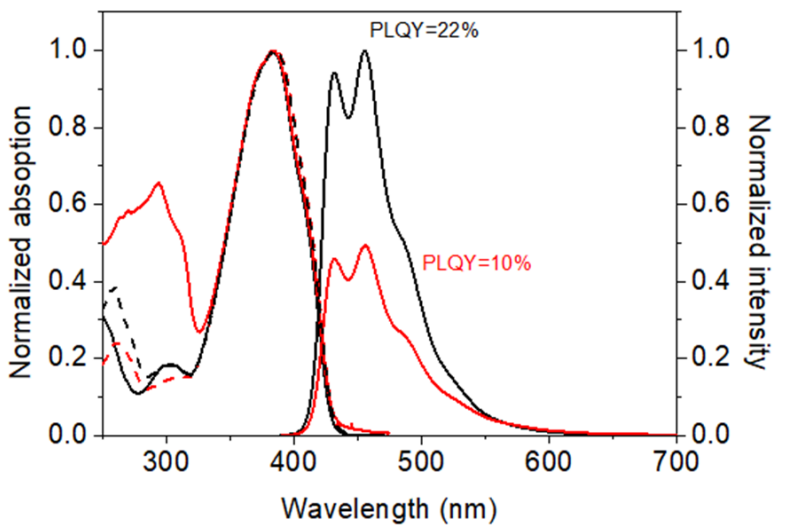

Figure 5. Absorbance (plain), emission (plain, excitation: $380 \mathrm{~nm}$ ) and excitation (dashed, emission: $450 \mathrm{~nm}$ ) spectra of $\mathbf{K s i}_{\text {[BTTT-2] (red) and BTTT- }}$ 2 (black) in $\mathrm{CH}_{2} \mathrm{Cl}_{2}$ solution (emission spectra of $\mathrm{K}_{\mathrm{si}}$ [BTTT-2] and BTTT-2 were recorded with solutions presenting the same optical density at $380 \mathrm{~nm}$ ).

We report the synthesis of the first mesogenic donor-acceptor POM-based hybrid using a modular synthetic strategy that will 
allow diversifying this class of organic/inorganic hybrid material. The hybrid compound was entirely characterized in the solution state, notably by electrochemistry, which confirmed its D-A character. In the solid state, the compound spontaneously selforganizes in a smectic-like multi-layered structure alternating nanosegregated donor-BTTT and acceptor-POM sublayers. Interestingly, the organizations of the POM and BTTT sub-units are similar to those observed for the precursor compounds BTTT2 and $\mathrm{Ksi}_{\mathrm{i}}[\mathrm{I}]$. In particular, the branched terminal aliphatic chains impose a significant tilt of BTTT units in the hybrid as in the organic precursor. Furthermore, $\mathbf{K}_{\mathbf{s i}_{i}}[\mathbf{B T T T}-2]$ and $\mathbf{K}_{\mathbf{s i}_{i}}[\mathbf{l}]$ exhibit comparable quasi-hexagonal rectangular arrangements of POM and TBA. The predictability of the individual sub-unit organizations will facilitate the design of future generations of hybrids in view of the formation of regular nano-arrays. Preliminary photophysical studies of this D-A hybrid show that the fluorescence of the BTTT unit is considerably quenched both in solution and in the solid state owing to the formation of intramolecular charge-separated states. We anticipate that the design of such self-organized donor-acceptor POM-based hybrid could lead to a new class of multi-functional POM-based materials, easily processable, and potentially suitable for electronic and optoelectronic applications.

\section{Acknowledgements}

We gratefully acknowledge MiChem Labex, within the Investissement d'Avenir program under reference ANR-11-IDEX004-02, for a postdoctoral fellowship to X.Z. The work was also supported by the French National Research Agency (EXPAND Project Grant ANR 14-CE08-0002) and by the CNRS (PICS N ${ }^{\circ}$ 8085). The Chevreul Institute (FR 2638), the Ministère de l'Enseignement Supérieur et de la Recherche, the Région Hauts de France and FEDER are acknowledged for the use of time resolved emission platform. Olivier Devos and Julien Dubois are acknowledged for technical assistance on time resolved emission experiments.

Keywords: Organic inorganic hybrids • Self-assembly • Nanosegregated materials $\bullet$ donor acceptor systems • polyoxometalates.

[1] a) H. lino, T. Usui, J. Hanna, Nat. Commun. 2015, 6, 6828; b) F. Lincker, A. J. Attias, F. Mathevet, B. Heinrich, B. Donnio, J. L. Fave, P. Rannou, R. Demadrille, Chem. Commun. 2012, 48, 3209-3211; c) A. R. Murphy, J. M. J. Fréchet, Chem. Rev. 2007, 107, 1066-1096; d) L. Mazur, A. Castiglione, K. Ocytko, F. Kameche, R. Macabies, A. Ainsebaa, D. Kreher, B. Heinrich, B. Donnio, S. Sanaur, E. Lacaze, J. L. Fave, K. Matczyszyn, M. Samoc, J. W. Wu, A. J. Attias, J. C. Ribierre, F. Mathevet, Org. Electron. 2014, 15, 943-953.

[2] a) T. Han, I. Bulut, S. Méry, B. Heinrich, P. Lévêque, N. Leclerc, T. Heiser, J. Mater. Chem. C 2017, 5, 10794-10800; b) J. F. Qu, B. R. Gao, H. K. Tian, X. J. Zhang, Y. Wang, Z. Y. Xie, H. Y. Wang, Y. H. Geng, F. S. Wang, J. Mater. Chem. A 2014, 2, 3632-3640; c) P. O. Schwartz, L. Biniek, E. Zaborova, B. Heinrich, M. Brinkmann, N. Leclerc, S. Méry, J. Am. Chem. Soc. 2014, 136, 5981-5992; d) J. M. Mativetsky, M. Kastler, R. C. Savage, D. Gentilini, M. Palma, W. Pisula, K. Mullen, P. Samori, Adv. Funct. Mater. 2009, 19, 2486-2494; e) K. J. Lee, J. H. Woo, Y. Xiao, E. Kim, L. M. Mazur, D. Kreher, A. J. Attias, K. Matczyszyn, M. Samoc,
B. Heinrich, S. Mery, F. Fages, L. Mager, A. D'Aleo, J. W. Wu, F. Mathevet, P. Andre, J. C. Ribierre, RSC Adv. 2016, 6, 57811-57819.

[3] a) T. Sakurai, S. Yoneda, S. Sakaguchi, K. Kato, M. Takata, S. Seki, Macromolecules 2017, 50, 9265-9275; b) D. Ley, C. X. Guzman, K. H. Adolfsson, A. M. Scott, A. B. Braunschweig, J. Am. Chem. Soc. 2014, 136, 7809-7812; c) Y. M. Xiao, D. L. Zeng, L. M. Mazur, A. Castiglione, E. Lacaze, B. Heinrich, B. Donnio, D. Kreher, A. J. Attias, J. C. Ribierre, F. Mathevet, Polym. J. 2017, 49, 31-39.

[4] A. R. Mallia, P. S. Salini, M. Hariharan, J. Am. Chem. Soc. 2015, 137, 15604-15607.

[5] S. B. Jin, M. Supur, M. Addicoat, K. Furukawa, L. Chen, T. Nakamura, S. Fukuzumi, S. Irle, D. L. Jiang, J. Am. Chem. Soc. 2015, 137, 7817-7827.

[6] a) Y. L. Wu, N. E. Horwitz, K. S. Chen, D. A. Gomez-Gualdron, N. S. Luu, L. Ma, T. C. Wang, M. C. Hersam, J. T. Hupp, O. K. Farha, R. Q. Snurr, M. R. Wasielewski, Nat. Commun. 2017, 9, 466-472; b) M. Hecht, T. Schlossarek, M. Stolte, M. Lehmann, F. Wurthner, Angew. Chem., Int. Ed. 2019, 58, 12979-12983.

[7] Y. F. Han, Y. K. Tian, Z. J. Li, F. Wang, Chem. Soc. Rev. 2018, 47, 51655176.

[8] M. Lehmann, M. Dechant, M. Lambov, T. Ghosh, Acc. Chem. Res. 2019, 52, 1653-1664.

[9] K. Goossens, K. Lava, C. W. Bielawski, K. Binnemans, Chem. Rev. 2016, 116, 4643-4807.

[10] a) K. Tanabe, Y. Suzui, M. Hasegawa, T. Kato, J. Am. Chem. Soc. 2012, 134, 5652-5661; b) J. H. Olivier, J. Barbera, E. Bahaidarah, A. Harriman, R. Ziessel, J. Am. Chem. Soc. 2012, 134, 6100-6103.

[11] B. Dong, H. Maeda, Chem. Commun. 2013, 49, 4085-4099.

[12] T. Kato, J. Uchida, T. Ichikawa, T. Sakamoto, Angew. Chem., Int. Ed. 2018, 57, 4355-4371.

[13] O. Ostroverkhova, Chem. Rev. 2016, 116, 13279-13412.

[14] Special issue devoted to polyoxometalates: L. Cronin and

A. Müller, Chem. Soc. Rev., 2012, 41(22), 7325-7648.

[15] W. Li, L. X. Wu, Polym. Int. 2014, 63, 1750-1764.

[16] a) J. J. Walsh, A. M. Bond, R. J. Forster, T. E. Keyes, Coord. Chem. Rev. 2016, 306, 217-234; b) Y. C. Ji, L. J. Huang, J. Hu, C. Streb, Y. F. Song, Energy Environ. Sci. 2015, 8, 776-789; c) G. Izzet, F. Volatron, A. Proust, Chem. Rec. 2017, 17, 250-266; d) Y. Ben M'Barek, T. Rosser, J. Sum, S. Blanchard, F. Volatron, G. Izzet, R. Salles, J. Fize, M. Koepf, M. Chavarot-Kerlidou, V. Artero, A. Proust, Acs Appl Energ Mater 2020, 3, 163-169.

[17] a) Y. Martinetto, B. Pegot, C. Roch-Marchal, B. Cottyn-Boitte, S. Floquet, Eur. J. Inorg. Chem. 2020, 2020, 228-247; b) A. Misra, K. Kozma, C. Streb, M. Nyman, Angew. Chem., Int. Ed. 2020, 59, 596-612.

[18] a) A. Klaiber, S. Polarz, ACS Nano 2016, 10, 10041-10048; b) C. G. Lin, W. Chen, S. Omwoma, Y. F. Song, J. Mater. Chem. C 2015, 3, 15-18; c) S. Landsmann, C. Lizandara-Pueyo, S. Polarz, J. Am. Chem. Soc. 2010, 132, 5315-5321.

[19] a) F. A. Black, A. Jacquart, G. Toupalas, S. Alves, A. Proust, I. P. Clark, E. A. Gibson, G. Izzet, Chem. Sci. 2018, 9, 5578-5584; b) B. Matt, X. Xiang, A. L. Kaledin, N. N. Han, J. Moussa, H. Amouri, S. Alves, C. L. Hill, T. Q. Lian, D. G. Musaev, G. Izzet, A. Proust, Chem. Sci. 2013, 4, 1737-1745.

[20] Z. F. Yao, J. Y. Wang, J. Pei, Cryst. Growth Des. 2018, 18, 7-15.

[21] a) I. Tahar-Djebbar, F. Nekelson, B. Heinrich, B. Donnio, D. Guillon, D. Kreher, F. Mathevet, A. J. Attias, Chem. Mater. 2011, 23, 4653-4656; b) D. L. Zeng, I. Tahar-Djebbar, Y. M. Xiao, F. Kameche, N. Kayunkid, M. Brinkmann, D. Guillon, B. Heinrich, B. Donnio, D. A. Ivanov, E. Lacaze, D. Kreher, F. Mathevet, A. J. Attias, Macromolecules 2014, 47, 17151731 ; c) Y. M. Xiao, X. L. Su, L. Sosa-Vargas, E. Lacaze, B. Heinrich, B. Donnio, D. Kreher, F. Mathevet, A. J. Attias, CrystEngComm 2016, 18, 4787-4798.

[22] V. Duffort, R. Thouvenot, C. Afonso, G. Izzet, A. Proust, Chem. Commun. 2009, 6062-6064.

[23] G. Toupalas, J. Karlsson, F. A. Black, A. Masip-Sánchez, X. López, Y. Ben M'Barek, S. Blanchard, A. Proust, S. Alves, P. Chabera, I. P. Clark, T. Pullerits, J. M. Poblet, E. A. Gibson, G. Izzet, Angew. Chem., Int. Ed., https://doi.org/10.1002/anie.202014677.

[24] Y. Shimizu, H. Monobe, B. Heinrich, D. Guillon, K. Oikawa, K. Nakayama, Mol. Cryst. Liq. Cryst. 2009, 509, 948-954. 
[25] S. Aoki, T. Kurashina, Y. Kasahara, T. Nishijima, K. Nomiya, Dalton Trans. 2011, 40, 1243-1253.

[26] S. Marzouk, A. Khalfallah, B. Heinrich, J. E. Khiari, A. Kriaa, S. Méry, J. Fluorine Chem. 2017, 197, 15-23. 